\title{
REMOVING THE SHADOW OF SUSPICION: \\ THE EFFECTS OF APOLOGY VERSUS DENIAL FOR REPAIRING COMPETENCE- \\ VERSUS INTEGRITY-BASED TRUST VIOLATIONS
}

\author{
Peter H. Kim \\ University of Southern California \\ Dept. of Management and Organization \\ Bridge Hall 307F \\ Los Angeles, CA 90089-1421 \\ Tel: (213) 740-7947 \\ Fax: (213) 740-3582 \\ e-mail: kimpeter@usc.edu \\ Donald L. Ferrin \\ State University of New York at Buffalo \\ Department of Organization and Human Resources \\ 274 Jacobs Hall \\ Buffalo, NY 14260-4000 \\ Tel: (716) 645-7900 \\ Fax: (716) 645-2863 \\ e-mail: dlferrin@buffalo.edu \\ Cecily D. Cooper \\ Southern Methodist University \\ Dept. of Management \& Organizations \\ P.O. Box 750333 \\ Dallas, Texas 75275-0333 \\ Tel: (214) 768-1261 \\ Fax: (214) 768-4099 \\ e-mail: cooperc@mail.cox.smu.edu \\ Kurt T. Dirks \\ Washington University in St. Louis \\ John M. Olin School of Business \\ One Brookings Drive \\ St. Louis, MO 63130 \\ Tel: (314) 935-5206 \\ Fax: (314) 935-6359 \\ e-mail: dirks@olin.wustl.edu
}

\section{Journal of Applied Psychology, in press}

The authors would like to thank William Bottom, Stuart Bunderson, Claus Langfred, and Raymond Sparrowe for their comments. This study was supported by a grant from the University of Southern California's James H. Zumberge Research and Innovation Fund. 


\title{
REMOVING THE SHADOW OF SUSPICION: \\ THE EFFECTS OF APOLOGY VERSUS DENIAL FOR REPAIRING COMPETENCE- \\ VERSUS INTEGRITY-BASED TRUST VIOLATIONS
}

\begin{abstract}
Two studies were conducted to examine the implications of an apology versus a denial for repairing trust after an alleged violation. Results reveal that trust was repaired more successfully when mistrusted parties: 1) apologized for violations concerning matters of competence but denied culpability for violations concerning matters of integrity, and 2) had apologized for violations when there was subsequent evidence of guilt, but had denied culpability for violations when there was subsequent evidence of innocence. Supplementary analyses also reveal that the interactive effects of violation-type and violation-response on participants' trusting intentions were mediated by their trusting beliefs. Combined, these findings provide needed insight and supporting evidence concerning how trust might be repaired in the aftermath of a violation.
\end{abstract}

Key Words: Trust, perception, apology, denial, competence, integrity, guilt, innocence 
Over the past decades, researchers have produced considerable evidence that trust can offer numerous benefits for individuals and organizations. The presence of trust has been found, for example, to facilitate cooperation between interdependent actors, improve job attitudes, increase organizational commitment and performance, and enable the emergence of new organizational forms (see Dirks \& Ferrin, 2002; Kramer, 1999 for meta-analytic and narrative reviews). Through such studies, researchers have largely emphasized the positive qualities of trust, and the constructive processes through which trust develops.

Yet, in many cases, an individual's positive expectations may be violated, resulting in reduced trust, and a need to repair trust. Tyler and Kramer (1996) noted that, as a result of widely publicized organizational practices such as the high compensation of CEOs, organizations have experienced declining trustworthiness in the eyes of their employees and members of other organizations. Consistent with this assertion, Robinson and Rousseau (1994) discovered that fifty-five percent of their respondents reported that their employer had violated a psychological contract and that this violation significantly reduced trust. Indeed, the popular press has noted that "a seemingly endless stream of bad news alleging widespread management negligence and malfeasance is chipping away at the trust vital to a free-market system" (Byrne, 2002, p.31).

The apparent frequency with which trust has been broken suggests that managers may often need to repair it. However, there are a variety of reasons why the process of repairing trust may be more difficult, and require different strategies, than building trust initially. One of the challenges of repairing trust is that the magnitude of the required increase in trust may actually be greater than in initial trust development. In the initial stages of a relationship, individuals exhibit surprisingly high levels of trust because they operate on the assumption that trust is warranted as long as there is no evidence to the contrary (McKnight, Cummings, \& Chervany, 
1998). This provides an elevated platform for moving to even higher levels of trust based on experience. But a trust violation invalidates the "trustworthy until proven otherwise" assumption, causing trust to plunge to a level that may be below the initial trust level. A second challenge of repairing trust is that mistrusted parties must not only reestablish positive expectations, but also overcome negative expectations. Third, information about the violation may remain particularly salient, reinforcing the low trust level despite efforts by the mistrusted party to demonstrate trustworthiness (Slovic, 1993). In sum, the trust repair process may differ qualitatively and quantitatively from initial trust development. Hence, different theoretical and empirical approaches may be needed to understand how it occurs.

Despite the importance of addressing such issues, surprisingly few studies have directly examined how trust might be repaired. A handful of researchers has considered the ways in which mistrusted parties might repair trust by offering some verbal response to these trust violations. Yet, even across this small number of studies (as well as related research on social accounts, impression management, and the re-establishment of cooperation in social dilemmas), there seems to be little consensus regarding what kind of response this should be. The difficulty of choosing the appropriate response for repairing trust is even further complicated by the fact that mistrusted parties may often (a) need to address actions that they did not commit, and even (b) repair trust with people whom these violations did not directly harm.

These considerations raise some natural questions. Are some types of responses more effective for repairing trust than others, or are there contingencies that affect whether one type of response might be preferred? Moreover, since trust may be determined by multiple dimensions, are some responses more effective for repairing certain aspects of trust than others, and under what conditions might this be the case? Given the crucial role trust plays in organizational life, it 
is essential that scholars and practitioners alike acquire substantive answers to such questions. The purpose of this article is to begin addressing these issues by investigating the relative benefits of two of the most common responses to a trust violation, apology and denial, for trust repair. In the present study, we focus on cases in which parties have had limited prior interaction and/or the relationship is in the emergent stages (as opposed to a relationship with a long history). We focus on such cases due to the importance of these early interactions for defining the nature and quality of the future relationship.

\section{Trust Formation, Violation and Repair}

Consistent with past research, we define trust as a psychological state comprising the intention to accept vulnerability based upon positive expectations of the intentions or behavior of another (Rousseau, Sitkin, Burt, \& Camerer, 1998). Following McKnight et al. (1998), we refer to the two elements of this definition as "trusting intentions" (i.e., a willingness to make oneself vulnerable to another in the presence of risk) and "trusting beliefs" (e.g., the beliefs about another's integrity or competence that may lead to trusting intentions). Thus, we recognize that trust is a fairly complex, multifaceted construct, and we presume that trust repair efforts will usually need to focus on trusting beliefs as well as trusting intentions. Accordingly, we define trust repair efforts as activities directed at making a trustor's trusting beliefs and trusting intentions more positive after a violation is perceived to have occurred.

Although trust is generally thought to develop gradually over time (e.g., Lewicki \& Wiethoff, 2000), recent observations suggest that individuals can exhibit surprisingly high levels of trust for others even without a history of interaction (McKnight et al., 1998; Meyerson, Weick, \& Kramer, 1996). McKnight et al. (1998) note that this high initial trust can arise for a variety of reasons, including an individual's disposition to trust (i.e., personality); belief that 
impersonal structures such as regulations and laws support one's likelihood of success in a given situation (i.e., institution-based trust); and rapid, cognitive cues arising from group membership, reputations, and stereotypes. These researchers also note, however, that such trust can be fragile due to the tentative and assumption-based nature of these antecedents.

Parties may often behave in ways that can violate trust, such as by intentionally exploiting dependencies or by neglecting to fulfill expectations. However, research suggests that trust can be damaged even when they have not committed such infractions. Empirical studies have found that people can be quite willing to believe unsubstantiated allegations of such acts, despite the difficulties of determining whether such allegations are accurate (e.g., Bell \& Loftus, 1989; Penrod \& Cutler, 1995; Ross, Ceci, Dunning, \& Toglia, 1994). And when this occurs, it appears that the onus is frequently placed on the accused party to remove the shadow of suspicion (Hendry, Peacock, \& Shaffer, 1989).

The present studies, therefore, assume that perceivers exhibit at least some initial trust in parties with whom they have had no history of interaction, and that unproven allegations of untrustworthy behavior would create suspicion sufficient to violate this trust. In other words, these studies rely on the intuitive and scientifically justified notion that allegations of untrustworthy behavior would cause perceivers' trust in the accused party to be lower than what it would have otherwise been. We first conduct a pilot study to validate this assumption. Our two main studies then assess perceivers' beliefs in an accused party's trustworthiness (i.e., trusting beliefs) and intentions to be vulnerable to the accused party's actions (i.e., trusting intentions), after that party has responded to the accusation, to determine the extent to which trust has been repaired. 


\section{Responding to a Trust Violation}

Efforts to understand how to repair trust have led trust researchers to focus on two different ways of responding to a trust violation - apology and denial. Apology is defined as a statement that acknowledges both responsibility and regret for a trust violation. Denial, in contrast, is defined as a statement whereby an allegation is explicitly declared to be untrue (i.e., the statement acknowledges no responsibility and hence no regret). A growing body of literature that assesses the implications of such responses suggests that each may exert an important influence on trust. However, these studies have reached seemingly conflicting conclusions about which of the two responses may repair trust more effectively than the other.

Some discussions suggest that trust may be repaired more successfully if mistrusted parties identify, acknowledge, and assume some "ownership" for the trust-destroying events that occurred (Lewicki \& Bunker, 1996). Although apologizing acknowledges guilt, which alone should lower trust, its concomitant expression of regret signals an intention to avoid similar violations in the future, which should reduce perceivers' concerns about continued vulnerability and, thereby, improve trust. Thus, on a theoretical level, we can observe that the effectiveness of apology as a response to a trust violation depends on the notion that this response's benefits (due to potential redemption) would outweigh its costs (due to the confirmation of guilt).

This reasoning is supported by a wide array of empirical evidence. Findings indicate that victims of psychological harm generally have more favorable impressions of the perpetrator, experience more positive affect, and are more likely to refrain from severe aggression toward the perpetrator when the culprit apologizes for the wrongdoing, than when the culprit does not (Ohbuchi, Kameda, \& Agarie, 1989). Experimental studies of impression management reveal that the expression of remorse following a transgression can mitigate punishment (e.g., Schwartz, 
Kane, Joseph, \& Tedeschi, 1978). Moreover, research on social dilemmas demonstrates that, at least in short-term interactions, apology can be more effective for re-establishing cooperation after an opportunistic act than denial (Bottom, Gibson, Daniels, \& Murnighan, 2002). These findings suggest that individuals will exhibit more trusting beliefs in and trusting intentions toward an accused party if that party apologizes, rather than denies culpability, for a trust violation.

However, other research observes that an apology may fail to ameliorate the negative consequences of an accusation because it involves an acknowledgement of guilt (Schlenker, 1980). According to this view, such guilt would damage trust to a much greater degree than any benefits apology would garner with regard to signaling that the violation would be avoided in the future. Denial may, therefore, represent a more effective response to a trust violation than apology because it may lead individuals to give the accused party the benefit of the doubt. The disadvantage of denial is that it indicates that there is no need to rectify one's behavior, which may in turn raise concerns about the mistrusted party's future actions to the extent that there are any lingering questions about that party's culpability. Nevertheless, denial may still represent an effective response to the trust violation to the extent that this response's benefits (due to potential disconfirmation of guilt) outweigh its costs (due to the lower likelihood of redemption).

This notion is supported by Sigal et al. (1988), who asked participants to watch a videotape of a simulated debate in which one political candidate was accused of sexual or financial misconduct by the other. Sigal et al. found that the accused party received more votes and was considered to be more honest, ethical, and trustworthy, when that party denied culpability, rather than apologized, for the misconduct. Moreover, research on social accounts indicates that denials can help blunt future conflict and reduce negative reactions to harmful acts. 
For example, Riordan, Marlin, and Kellogg (1983) used fabricated reports of a fictitious senator having taken a bribe and found that subsequent character evaluations of the senator were less negative when the senator denied, rather than admitted, responsibility for the transgression. Thus, with regard to the relative benefits of apology versus denial for repairing trust, we can identify both theoretical and empirical reasons to justify a competing expectation - that individuals will exhibit more trusting beliefs in and trusting intentions toward an accused party if that party denies culpability, rather than apologizes, for a trust violation.

\section{Implications of Violation-Type}

One approach to addressing this apparent contradiction would be simply to determine which conclusion is valid and which is not. Yet it may also be possible to reconcile this contradiction. Indeed, one factor that may play a key role in determining whether apology or denial is more effective is whether the trust violation concerns matters of competence or integrity. These dimensions are particularly relevant for our research because they represent two of the most important qualities for determining trustworthiness (Barber, 1983; Butler \& Cantrell, 1984; Cook \& Wall, 1980; Mayer, Davis, \& Schoorman, 1995; Schindler \& Thomas, 1993). Expectations of "technically competent role performance" and expectations of "the persistence and fulfillment of the natural and moral social orders" have been considered to "involve some of the fundamental meanings of trust" (Barber, 1983, p.9), and this notion has been supported by ample empirical evidence (e.g., Butler \& Cantrell, 1984; Schindler \& Thomas, 1993). Moreover, research has shown that these dimensions offer important bases upon which individuals evaluate a variety of targets, including leaders (Pancer, Brown, \& Barr, 1999), job candidates (Cook \& Elmer, 1999), and potential collaborators (Kee \& Knox, 1970). Competence-based trust is defined as the trustor's perception that the trustee possesses the technical and interpersonal skills 
required for a job (Butler \& Cantrell, 1984). Integrity-based trust is defined as the trustor's perception that the trustee adheres to a set of principles that the trustor finds acceptable (Mayer et al., 1995).

Research on how individuals resolve discrepancies in their interpersonal perceptions reveals that there may be some inherent differences in the way people assess positive versus negative information about competence versus integrity (see Snyder \& Stukas, 1999, for a review). In particular, these studies suggest that although individuals tend to weigh positive information about competence more heavily than negative information about competence, they tend to weigh negative information about integrity more heavily than positive information about integrity (Madon, Jussim, \& Eccles, 1997; Martijn, Spears, Van der Plight, \& Jakobs, 1992). Reeder and Brewer (1979), furthermore, have explained such asymmetries through a schematic model of dispositional attribution, which suggests that attributions of competence and integrity are influenced by hierarchically-restrictive schemas.

Hierarchically-restrictive schemas assume that being at one end of a continuum for a given attribute will restrict one's behavior, whereas being at the other end of that continuum will not. People intuitively believe, for example, that those with high competence are capable of exhibiting performance at many levels, depending on their motivation and task demands, whereas those with low competence can only perform at levels that are commensurate with or lower than their level of competence. For this reason, a single successful performance is considered to offer a reliable signal of competence, given the belief that those who are incompetent would not have been able to achieve that performance level. However, a single poor performance is typically discounted as a signal of incompetence, given that those who are 
competent or incompetent can each perform poorly in certain situations (e.g., when there is inadequate motivation or opportunity to perform well).

Similarly, people intuitively believe that those with high integrity will refrain from dishonest behaviors in any situation, whereas those with low integrity may exhibit either dishonest or honest behaviors depending on their incentives and opportunities. For this reason, a single honest behavior is typically discounted as a signal of honesty, given that those who are honest or dishonest can each behave honestly in certain situations (e.g., when there are benefits for behaving honestly or sufficient surveillance to prevent dishonest acts). However, a single dishonest behavior is considered to offer a reliable signal of low integrity, given the belief that only persons of low integrity will perform in dishonest ways.

Thus, hitting a home run once makes us home run hitters in the eyes of others even if we strike out afterward. In contrast, embezzling from a company once makes us an embezzler even if we do not engage in additional thefts in the next few days, months, or even years. These differences in the way people assess positive versus negative information about competence and integrity have been used in negotiation research to explain why negotiators are more likely to behave in ways that confirm certain kinds of feedback than others (Kim, Diekmann, \& Tenbrunsel, 2003). However, the implications of these studies may be extended even further to shed light on the ways in which interpersonal perceptions, specifically the perception of untrustworthiness, may be disconfirmed.

In particular, the notion that people weigh positive information about competence more heavily than negative information about competence suggests that it may be more effective to apologize rather than deny culpability for a competence-based trust violation. Although an apology confirms that the violation was committed, this information will not be considered to be 
particularly diagnostic of one's inherent competence, since the incident may be considered an anomaly that would not necessarily be repeated in the future. The negative effect on trust from an apology's admission of guilt should, therefore, be less significant than its positive effect on trust from signaling the intent to prevent further violations, because people may be willing to believe that that the mistrusted party will demonstrate that he/she possesses positive competence in the future. Denial, in contrast, will limit perceived guilt, but also limit signals of intended redemption, since this response indicates that there will be no effort to change one's behavior. Thus, given that the benefits of reducing non-diagnostic negative-competence information (i.e., perceived guilt) are outweighed by the costs of reducing expectations of highly diagnostic positive-competence information (i.e., perceived redemption), an apology should ultimately be more effective than denial for repairing trust after an alleged competence-based trust violation.

In contrast, the notion that people will weigh negative information about integrity more heavily than positive information about integrity suggests that apologizing for integrity-based trust violations will not be as effective as denying culpability. Apologizing for such violations would again confirm guilt, but in this case, such guilt would be perceived to offer a reliable signal that one lacks integrity (i.e., since people believe that a lack of integrity would only be exhibited by those who do not possess it). And because individuals tend to discount positive information about integrity (i.e., integrity cannot be proven), the belief that one lacks integrity, once established, will be difficult to disconfirm (e.g., Reeder \& Coovert, 1986). Denial, in contrast, would again limit perceived guilt and signals of intended redemption. However, given that the benefits of reducing highly diagnostic negative-integrity information (i.e., perceived guilt) will outweigh the costs of reducing expectations of non-diagnostic positive-integrity 
information (i.e., perceived redemption), denial should ultimately be more effective than apology for repairing trust after an alleged integrity-based trust violation.

Hypothesis 1a: When trust violations concern matters of competence, individuals will exhibit more positive trusting beliefs in the accused party if that party responds with an apology rather than a denial. When trust violations concern matters of integrity, individuals will exhibit more positive trusting beliefs in the accused party if that party responds with a denial rather than an apology.

Hypothesis 1b: When trust violations concern matters of competence, individuals will exhibit more positive trusting intentions toward the accused party if that party responds with an apology rather than a denial. When trust violations concern matters of integrity, individuals will exhibit more positive trusting intentions toward the accused party if that party responds with a denial rather than an apology.

\section{Study 1}

The purpose of Study 1 was to examine the implications of different types of responses (apology or denial) for increasing trust from pre-existing low levels, as would exist after an alleged transgression. Thus, we designed a laboratory experiment in which participants watched a videotape of a job applicant at an accounting firm, who had been accused of incorrectly filing a tax return in her last job, and then rated the applicant's trustworthiness after she explained what had occurred. Following guidance provided by Dobbins, Lane, and Steiner (1988), we chose this experimental method and laboratory setting so that we could draw clear conclusions about causality. 


\section{Method}

This study implemented a 2 (Violation-type: competence vs. integrity) x 2 (Violationresponse: apology vs. denial) between-subjects design. Participants were randomly assigned to the four study conditions. Each participant represented a unit of analysis.

\section{Participants}

Sixty-three undergraduate students enrolled in introductory organizational behavior and human resources management courses participated in this study for course credit, and 137 graduate business students from four negotiation courses participated in this study as part of an in-class exercise. Thus, the total sample size was 200. Participants in the undergraduate sample were sixty-one percent male, an average of twenty-two years old, and possessed an average of one year of full-time work experience. Participants in the graduate sample were fifty-six percent male, an average of twenty-six years old, and possessed an average of three and a half years of full-time work experience. We included undergraduate and graduate students in the study to enhance the generalizability of the results (due to increased breadth of work experience and demographic diversity in the sample) and statistical power.

\section{Task}

Participants were given materials that asked them to assume the role of a manager who was in charge of hiring, and subsequently managing, a senior-level tax accountant. If hired, the candidate would be offered a one-year contract because it was the policy of the firm to employ all Senior Tax Accountants under one-year contracts with renewal contingent upon annual performance evaluations. Participants were told that, to expedite the hiring process, a recruiter from the firm had already interviewed the applicants and that these interviews had been videotaped and transcribed so participants could quickly and conveniently assess the applicant 
pool. Participants were then given the transcript for one of these interviews and shown the accompanying video clip so they could provide their own evaluation of the applicant. After watching the interview, participants completed a questionnaire.

\section{Manipulations}

Four versions of this interview were filmed with a video crew and actors in accordance with our $2 \times 2$ experimental design. The bulk of each version contained identical video footage; only the segments containing the two manipulations differed across study conditions. During the course of the interview, the recruiter disclosed to the job applicant that she had contacted some of the applicant's references from the previous employer and that these references informed the recruiter that the applicant had been involved with an accounting-related violation in her previous job. The framing of, and response to, this trust violation represented the study manipulations.

Violation-type. The trust violation was framed as either a competence- or integrityrelated matter. The alleged violation was described so that it was consistent with the conceptual definitions of competence and integrity presented earlier in the article. In both conditions, the job applicant was accused of filing an incorrect tax return that understated a client's capital gains income. In the competence condition, the job applicant was accused of filing the incorrect return due to inadequate knowledge of the relevant tax codes. In the integrity condition, the job applicant was accused of filing the incorrect return intentionally. In both cases, the information was hearsay. The recruiter did not have evidence of the candidate's guilt or innocence.

Violation-response. Immediately after the trust violation was mentioned, the job candidate responded to the allegation by either apologizing or denying responsibility for the act in question. In the apology condition, the candidate admitted responsibility for the trust 
violation, apologized for the infraction, and stated that such an incident would not happen again. In the denial condition, the candidate denied responsibility for the trust violation, attributed the allegation to bad office politics at the previous firm, and stated that the firm would not have to worry about her committing such an infraction if she were hired.

\section{Measures}

Several measures were developed to test the study predictions (see Appendix). Separate multi-item scales were adapted to assess the two trusting beliefs that were of interest in this study (i.e., perceived competence and perceived integrity). Additionally, three separate measures were used to assess participants' trusting intentions toward the candidate. We used a version of Mayer and Davis’s (1999) “willingness to risk” scale to obtain a general assessment of trusting intentions, and we developed two other measures (intention to hire and to assign job responsibilities) that also capture participants' willingness to make themselves vulnerable to the accused party, but in a manner that is more relevant to this specific context.

Perceived competence. Three items were adapted from Mayer and Davis (1999) to assess perceptions of the job applicant's competence. Since the Mayer and Davis (1999) items were designed to assess the trustworthiness of top management, we altered the items slightly to increase their relevance for the present study.

Perceived integrity. Three items were used to assess perceptions of the job applicant's integrity. Similar to the competence scale, this scale was also based on the integrity scale used by Mayer and Davis (1999), yet altered to be more relevant to the present study.

Willingness to risk. Three items were used to measure how much the participants, in their role as manager, were willing to put themselves at risk to the candidate. These items were adapted from a trust scale used by Mayer and Davis (1999). One item was reversed-scored. 
Hiring. Participants were asked to rate the likelihood that they would hire the job applicant on a 7-point Likert scale with anchors of "definitely" and "definitely not." This item was reversed-scored.

Job responsibilities. After responding to the hiring question, participants were instructed to assume that they had hired the job applicant, and five items were used to assess the level of job responsibilities that should be assigned to the candidate. The items were created to correspond with the video, focusing on specific issues that could arise in an accounting firm.

\section{Pilot Study}

A pilot study was conducted with a separate set of 71 undergraduates to determine whether participants would indeed possess some initial trust in the job candidate and that unproven allegations of untrustworthy behavior would be sufficient to violate this trust. ${ }^{1}$ This pilot study, therefore, asked participants to watch the videotaped interviews and then assessed participants' trust in the candidate immediately before and immediately after the alleged competence- or integrity-based violation (but before the candidate had offered a response).

Means and standard deviations by condition for this pilot study are reported in Table 1. Paired $t$ tests revealed that participant assessments of the candidate's competence $(t(34)=14.21, p<$ $.001)$ and integrity $(t(34)=8.80, p<.001)$, as well as participants' willingness to risk $(t(34)=$ $10.21, p<.001)$, hire $(t(34)=8.31, p<.001)$, and assign job responsibilities to the candidate $(t(34)=11.32, p<.001)$ were all significantly lowered by allegations that concerned matters of competence. Similarly, paired t-tests revealed that participant assessments of the candidate's competence $(t(37)=9.70, p<.001)$ and integrity $(t(37)=11.52, p<.001)$, as well as participants' willingness to risk $(t(37)=10.33, p<.001)$, hire $(t(37)=10.30, p<.001)$, and

\footnotetext{
${ }^{1}$ These issues were examined in a pilot study, rather than the primary study, to avoid potential demand effects (from having participants answer the same set of questions three times) that could have clouded the results.
} 
assign job responsibilities to the candidate $(t(37)=10.87, p<.001)$ were all significantly lowered by allegations that concerned matters of integrity. ${ }^{2}$ These findings provide clear and consistent support for our assumption that unproven allegations of untrustworthy behavior are sufficient to violate participants' initial trust in parties with whom they have had no history of interaction, and thereby demonstrates the suitability of this context for investigating trust repair.

\section{Results for Study 1}

\section{Manipulation Checks, Descriptive Statistics, and Convergent and Discriminant Validity}

Participants responded to three manipulation check questions (see Appendix) that assessed whether they recognized the nature of the violation (competence vs. integrity) and the response to the violation (apology vs. denial). Manipulation checks revealed that the manipulations were successful. Of the 200 participants, 171 answered all three questions correctly $(85.5 \%), 28(14.0 \%)$ missed one question, and $1(0.5 \%)$ missed two questions.

Confirmatory factor analyses of the trusting beliefs and trusting intentions variables (perceived competence, perceived integrity, willingness to risk, hiring, and job responsibilities) indicated a good fit and supported convergent validity for a five-factor model $\left(X^{2}=130.30, d f=\right.$ $81, \mathrm{CFI}=.99, \mathrm{NFI}=.99, \mathrm{TLI}=.99, \mathrm{RMSEA}=.055$, all item-factor loadings $\geq|.58|(p<.001)$ Discriminant analyses (Bagozzi \& Phillips, 1982) indicated that the hypothesized 5-factor model fits the data significantly better than any of the more parsimonious models, supporting the discriminant validity of the constructs. Specifically, the best fitting four-factor model, in which the correlation between Willingness to Risk and Job Responsibilities was set at 1.0, had $X^{2}=$ 140.29, $d f=82$, increase in $X^{2}=9.99(p<.01)$. The one-factor model had $X^{2}=918.07, d f=91$,

\footnotetext{
${ }^{2}$ The fact that alleged competence violations also lowered perceived integrity and that alleged integrity violations also lowered perceived competence may be due to our stopping the videotaped interviews immediately after the allegation, which may have raised questions about whether information about inadequate integrity or inadequate competence, respectively, would have been forthcoming.
} 
increase in $X^{2}=787.77(p<.001)$. Table 2 presents the descriptive statistics, reliabilities, and inter-correlations of the study variables. Table 3 reports variable means and standard deviations by condition.

\section{Hypothesis Tests}

We used effects coding (Cohen \& Cohen, 1983) to create the independent and interaction terms for the subsequent regression analyses. Effects coding produces results identical to ANOVA, yet also facilitates the testing of mediation by generating the ANOVA results in regression form. Following the practice of effects coding, the two response conditions and the two types of trust violation are each represented in the regression equations by one effects coding variable. The violation-response variable was labeled "Apology/Denial" (coded as 1/-1) and the violation-type variable was labeled "Competence/Integrity" (coded as 1/-1).

Table 4 presents the results of the regression equations testing Hypotheses $1 \mathrm{a}$ and $1 \mathrm{~b} .^{3}$ To test the prediction that the benefits of apology versus denial for repairing trusting beliefs and trusting intentions would depend on whether the violation concerned matters of competence or integrity, we created a multiplicative interaction term, combining the Apology/Denial and Competence/Integrity variables. We referred to this term in Table 4 as "Interaction." Since violation-type and violation-response were orthogonal as a result of our experimental design, the single-step regressions shown in equations 1-3 of Table 4 present results that are identical to hierarchical moderated regression analyses. Therefore, for the sake of parsimony only the single-step regressions are shown in Table 4.

To assess Hypotheses 1a and 1b, we interpreted the significance of the Interaction variable in equations 1 and 2. Although the predicted interaction was not supported for

\footnotetext{
${ }^{3}$ An alternative set of effects coding analyses that controlled for our use of graduate and undergraduate samples with a covariate revealed virtually identical results.
} 
perceived competence or willingness to risk, the significant betas in the regressions predicting perceived integrity $(\beta=.44, p<.001)$, hiring $(\beta=.20, p<.01)$, and job responsibilities $(\beta=.14, p$ $<.05)$ supported the predicted interaction. To explore these significant interaction effects, we conducted a post-hoc subgroup analysis for each of these three dependent variables (see Figures $1 \mathrm{~A}$ and $1 \mathrm{~B})$. The overall findings reveal that when the violation concerned matters of integrity, participants' perceptions of the candidate's integrity and their intentions to hire and to assign job responsibilities were all repaired more successfully when the mistrusted party denied culpability for the act in question, whereas when the violation concerned matters of competence, apology was generally the more effective response. Thus, Hypotheses $1 \mathrm{a}$ and $1 \mathrm{~b}$ received support.

\section{Mediation Analyses}

In order to provide a more complete and precise understanding of the trust repair process, we also examined whether the interaction effects of violation-type and violation-response on participants' trusting intentions would be mediated by their trusting beliefs (see Figure 2). This possibility is suggested by the fact that: a) the types of violations under consideration concern matters of competence or integrity, b) perceptions of competence and integrity represent two of the most important elements of trusting beliefs, and c) these trusting beliefs have been theorized to influence trusting intentions (e.g., Mayer et al., 1995; McKnight et al., 1998) (i.e., the beliefs that one holds about an individual should affect how one intends to act toward that party). By following Baron and Kenny's (1986) guidelines for testing mediation, we conducted regression analyses to examine: 1) the effect of the manipulations on perceived competence and integrity, 2) the effect of the manipulations on willingness to risk, hiring, and job responsibilities, and 3) the effect of the manipulations on willingness to risk, hiring, and job responsibilities while controlling for perceived competence and integrity. Equations 1, 2, and 3, respectively (see 
Table 4), show the results of these tests. Since our primary interest was whether trusting beliefs mediated the interaction of violation-type and violation-response on trusting intentions, we interpreted only the Interaction variable as the independent variable in the analysis.

Equation 1 indicates that the Interaction variable significantly influenced perceived integrity, but not perceived competence. Thus, only perceived integrity satisfied the first requirement for mediation. Equation 2 reveals that the Interaction variable exerted a significant effect on hiring and job responsibilities. Thus, the second requirement for mediation was satisfied for hiring and job responsibilities but not willingness to risk. Finally, Equation 3 reveals that the effects of the Interaction variable on hiring and job responsibilities became nonsignificant when the mediating variables were added to the model, but perceived integrity still exerted a significant effect on these dependent measures. Thus, we can conclude that perceived integrity fully mediated the relationship between the Interaction variable and both hiring and job responsibilities.

\section{Discussion}

These results support predictions that the relative effects of apology versus denial for repairing trust would depend on the type of violation. Participants' perceptions of the candidate's integrity, their willingness to hire, and their willingness to assign job responsibilities to the candidate were all repaired more successfully when the candidate apologized for violations that concerned matters of competence, but denied culpability for violations that concerned matters of integrity. Moreover, the results support the notion that the effects of violation-type (i.e., competence/integrity) and violation-response (i.e., apology/denial) on participants' trusting intentions (i.e., hiring and job responsibilities) would be mediated by their trusting beliefs (i.e., perceived integrity). 
Nevertheless, an important question remains unexplored. Although this study focused on the implications of apology versus denial for repairing trust in parties whose culpability in a violation is unknown, it is quite often the case that the accused party's guilt or innocence subsequently becomes known. Given the significant role such knowledge is likely to play in the determination of trust, it is worthwhile to examine whether the aforementioned findings will hold even after evidence about the accused party's guilt or innocence becomes clear. Thus, we designed a second study to examine this possibility.

\section{Study 2}

Our objective in Study 2 was to determine whether the relative benefits of apology versus denial for repairing trust after an alleged competence- versus integrity-based trust violation would persist even after the accused party's actual guilt or innocence is subsequently revealed. We, therefore, modified our first study to offer evidence concerning the mistrusted party's guilt/innocence after manipulating the type of violation (i.e., competence vs. integrity) and the type of response (i.e., apology vs. denial). To the extent that the effects of apology versus denial are primarily driven by their divergent implications for guilt, the interaction between violationtype and violation-response should disappear once actual guilt/innocence is controlled. However, our prior arguments have suggested that these responses would not only influence assessments of guilt but also assessments of intended redemption, and that such redemption will be weighed more heavily for matters of competence than integrity. This suggests that the relative benefits of apology versus denial for repairing trust after an alleged competence- versus integrity-based trust violation will generalize to cases in which the mistrusted party's actual guilt/innocence becomes known. 
This conclusion does not imply, however, that knowledge of guilt/innocence is irrelevant. Indeed, such knowledge is likely to play a central role in the determination of trust. First, evidence about innocence should of course positively affect trust, while evidence about guilt should negatively affect trust. Second, we expect that rather than eliminating the interaction between violation-type and violation-response, evidence about guilt or innocence will influence the relative benefits of apology versus denial. Specifically, guilt information in the aftermath of a denial would indicate that the denial was a lie, and thus foster lower levels of trust than if that party had offered an apology. Similarly, innocence information in the aftermath of an apology would also indicate that the original apology was a lie, and thus foster lower levels of trust than if that party had offered a denial. Thus, overall, we expect that the relative benefits of apology versus denial for repairing trusting beliefs and trusting intentions will depend on the availability of guilt/innocence information.

Hypothesis 2a: When there is evidence that the accused party is guilty, individuals will exhibit more positive trusting beliefs in the accused party if that party had responded with an apology rather than a denial. When there is evidence that the accused party is innocent, individuals will exhibit more positive trusting beliefs in the accused party if that party had responded with a denial rather than an apology.

Hypothesis $2 b$ : When there is evidence that the accused party is guilty, individuals will exhibit more positive trusting intentions toward the accused party if that party had responded with an apology rather than a denial. When there is evidence that the accused party is innocent, individuals will exhibit more positive trusting intentions toward the accused party if that party had responded with a denial rather than an apology. 


\section{Method}

Study 2 utilized a 2 (violation-type: competence vs. integrity) x 2 (violation-response: apology vs. denial) x 2 (confirmation: guilty vs. innocent) between-subjects design. Participants were randomly assigned to each of the eight study conditions.

\section{Participants}

To facilitate the comparison of results across our studies, undergraduate and graduate students were also used as participants in Study $2(N=444)$. Three hundred twenty undergraduate students enrolled in introductory organizational behavior courses participated in this study for course credit, and 124 graduate business students from two organizational behavior courses participated in this study as part of an in-class exercise. Undergraduate participants were $58 \%$ male, averaged 21 years of age, and had an average of seven months of full-time work experience and three years of part-time work experience. Graduate participants were $68 \%$ male, averaged 28 years of age, and had an average of four-and-a-half years of full-time work experience.

\section{Task and Manipulation}

Study 2 was identical to Study 1 except that, after watching the videotaped interview but prior to completing the questionnaire, participants received information that confirmed or disconfirmed the accusation against the candidate (i.e., the guilt/innocence manipulation). The guilt/innocence manipulation was provided through a memo from the company's Human Resources department, addressed to "all management in charge of hiring," stating that the State Board of Public Accountancy had investigated and ruled on the accusation. The memo summarized the ruling by concluding that the candidate was innocent/guilty, and noted that the State Board ruling was attached. The State Board ruling, in turn, provided a description of the 
investigation that was identical across conditions, and then provided a ruling that was consistent with our experimental manipulation. In the innocent condition, the Board ruled as follows: "A thorough independent audit of her client files indicates no evidence of malfeasance. Ms. Ballou's record is cleared of all charges. She will remain fully licensed as a Certified Public Accountant and retain all membership privileges in our association." In the guilty condition, the Board ruled as follows: "A thorough independent audit of her client files indicates evidence of malfeasance on the part of Ballou. Her record will reflect violation of tax codes 901.402(9) and 901.402(7) for this client. The Board deems that she will remain fully licensed as a Certified Public Accountant but the Board will reconsider this matter if there are future violations." These stimulus materials were created specifically for the experiment, and were printed on "official" letterhead so they would look realistic.

Measures

Study 2 used the same measures as were used in Study 1.

Results for Study 2

Manipulation Checks, Descriptive Statistics, and Convergent and Discriminant Validity

Participants responded to the same three manipulation check questions that were described in Study 1, and a fourth question that assessed the manipulation of guilt/innocence. Of the 444 participants, 327 (74\%) answered all four questions correctly, 92 (21\%) missed one question, $22(5 \%)$ missed two questions, and $3(0.7 \%)$ missed three questions.

Confirmatory factor analyses of the trusting beliefs and trusting intentions variables (perceived competence, perceived integrity, willingness to risk, hiring, and job responsibilities) indicated a good fit and supported convergent validity for a five-factor model $\left(X^{2}=256.14, d f=\right.$ $81, \mathrm{CFI}=.99, \mathrm{NFI}=.99, \mathrm{TLI}=.99, \mathrm{RMSEA}=.070$, all item-factor loadings $\geq|.52|(p<.001)$. 
Discriminant analyses (Bagozzi \& Phillips, 1982) indicated that the hypothesized 5-factor model fits the data significantly better than any of the more parsimonious models, supporting the discriminant validity of the constructs. Specifically, the best fitting four-factor model, in which the correlation between Willingness to Risk and Job Responsibilities was set at 1.0, had $X^{2}=$ 266.70, $d f=82$, increase in $X^{2}=10.56(p<.01)$. The one-factor model had $X^{2}=2,425.97, d f=$ 91, increase in $X^{2}=2,169.83(p<.001)$. Table 5 presents descriptive statistics, reliabilities, and inter-correlations for these variables. Table 6 reports variable means and standard deviations by condition.

\section{Hypothesis Tests}

We again used effects coding to facilitate the comparison of results across studies (see Table 7). ${ }^{4}$ The guilt/innocence condition was coded $-1 / 1$. Hypotheses $1 \mathrm{a}$ and $\mathrm{b}$, which predicted an interaction between violation-type and violation-response, were supported for four of the five dependent variables. The beta coefficients were significant for perceived integrity $(\beta=.32, p<$ $.001)$, willingness to risk $(\beta=.19, p<.001)$, hiring $(\beta=.10, p<.05)$, and the assignment of job responsibilities $(\beta=.09, p<.05)$. Post-hoc subgroup analyses (see Figures 3A and 3B) indicated that the pattern of results was consistent with Study 1: When the violation concerned matters of integrity, participants' perceptions of the candidate's integrity, their intentions to hire, willingness to risk, and their willingness to assign job responsibilities were all repaired more successfully when the mistrusted party denied culpability for the act in question, whereas when the violation concerned matters of competence, apology was the more effective response. Thus, Hypotheses $1 \mathrm{a}$ and $1 \mathrm{~b}$ received support even when information about the candidate's guilt/innocence had been revealed.

\footnotetext{
${ }^{4}$ An alternative set of effects coding analyses that controlled for our use of graduate and undergraduate samples with a covariate again revealed virtually identical results.
} 
Hypotheses $2 \mathrm{a}$ and $2 \mathrm{~b}$ predicted an interaction between violation-response and confirming information. We first noticed that evidence of innocence had a strong positive effect on all five dependent variables. Beyond this main effect, the interaction of violation-response and confirming information had a robust effect across all five dependent variables. The effect was highly significant for perceived competence $(\beta=-.15, p<.001)$, perceived integrity $(\beta=$ $.27, p<.001)$, willingness to risk $(\beta=-.13, p<.01)$, hiring $(\beta=-.30, p<.001)$, and willingness to assign job responsibilities $(\beta=-.16, p<.001)$. Consistent with our hypotheses, post-hoc subgroup analyses (see Figures 4A and 4B) indicated that evidence of guilt in the aftermath of a denial was damaging to trust relative to evidence of guilt in the aftermath of an apology, and that evidence of innocence in the aftermath of an apology was damaging to trust relative to evidence of innocence in the aftermath of a denial. The results also suggested a three-way interaction among violation-type, violation-response, and confirming information for hiring $(\beta=.08, p<$ $.05)$ and willingness to assign job responsibilities $(\beta=.09, p<.05)$. Post-hoc subgroup analyses indicated that responses that were inconsistent with subsequent evidence concerning guilt/innocence were more damaging to trust when the violation concerned matters of integrity than competence.

\section{Discussion}

The findings from this study replicate and extend the results from Study 1, indicating that the differential effectiveness of apology versus denial holds even after evidence concerning the candidate's guilt/innocence became known. However, the data also reveal that participants' perceptions of the candidate's competence, perceptions of the candidate's integrity, willingness to risk, willingness to hire, and willingness to assign job responsibilities were all repaired more successfully when the candidate had apologized rather than denied culpability for a violation 
when there was evidence of guilt, but denied culpability rather than apologized when there was evidence of innocence.

The fact that the relative benefits of apology versus denial for repairing trust depend on the type of violation (i.e., competence vs. integrity) even after the mistrusted party's guilt or innocence becomes known supports the notion that these responses do more than simply signal the mistrusted party's guilt or innocence. In this second study, the candidate's guilt/innocence was made clear, which allowed us to control for such considerations when examining the interaction of violation-type and violation-response. Thus, the continued interaction between the type of violation and type of response, after guilt/innocence information is provided, supports our argument that apology and denial not only affect assessments of guilt/innocence but also signal intended redemption, and that this redemption is weighed more heavily for matters of competence than integrity.

Nevertheless, the fact that evidence concerning guilt/innocence affected whether trust was repaired more successfully with an apology or a denial indicates that this information does play an important role. The finding that responses that were inconsistent with subsequent evidence could prove detrimental to trust, even if the evidence indicates innocence, supports our argument that the inconsistency would induce suspicion and hence reduce trust. Thus, we can conclude that simply selecting the most effective response for a given violation (i.e., apologizing for competence-based violations and denying culpability for integrity-based violations) can pose a risk for trust repair efforts, given that trust may be further damaged if the response is ultimately found to be untrue. 


\section{General Discussion}

The purpose of this research was to investigate the benefits of apology and denial for repairing trust. Although trust is widely acknowledged to play a central role in organizational life, surprisingly little research has examined how trust might be repaired. Moreover, the few studies that do exist seem to offer conflicting recommendations.

Our efforts to address these limitations reveal that trust was repaired more successfully when mistrusted parties: 1) apologized for violations concerning matters of competence but denied culpability for violations concerning matters of integrity, and 2) apologized when there was evidence of guilt but denied culpability when there was evidence of innocence. Thus, we can observe that each of the conclusions drawn by prior research concerning the relative effects of apology versus denial for repairing trust may hold depending on the type of violation and the availability of evidence concerning innocence or guilt.

\section{Importance of Considering Specific Trusting Beliefs}

Beyond these findings, this research also reveals that the implications of apology or denial on subsequent trusting intentions after an alleged competence- versus integrity-based violation were mediated by the accused party's perceived integrity (i.e., a trusting belief). These findings are noteworthy for several reasons. First, these results offer important insight into the mechanisms through which these types of violations and responses to those violations ultimately repair trust, and thus allow us to place greater confidence in our theoretical reasoning and conclusions. Second, given the likely difficulty of repairing trust in many situations, assessments of such specific trusting beliefs may prove particularly useful for determining whether and how the repair of trusting intentions might ultimately occur. 
Finally, the need to examine specific trusting beliefs is heightened by the possibility that they may be differentially influenced by various trust repair attempts. Although some effects were found for perceived competence, the strongest and most consistent patterns of findings were observed with perceived integrity. Thus, to the extent that there may be occasions when trusting intentions are repaired more effectively by improving one of these trusting beliefs rather than the other, we may gain greater insight into the trust repair process if we pay particular attention to these specific perceptions.

\section{Implications for Research on Interpersonal Perceptions}

These studies contribute to a growing body of research that examines how organizational actors resolve differences in their interpersonal perceptions. Research on how targets respond when they discover how they are being perceived by others suggests that potentially erroneous perceptions are not always repaired (see Snyder \& Stukas, 1999, for a review). Although there may be times when targets are able to disconfirm such perceptions through their behavior (e.g., by repairing trust), they often respond in ways that lead these perceptions to be confirmed (e.g., by becoming less trustworthy) or react in ways that neither validate nor dismiss these perceptions (e.g., by terminating the relationship or simply failing to repair trust) (e.g., Jussim, Eccles, \& Madon, 1996; Madon et al., 1997). Moreover, a growing body of research indicates that there may be important contingencies that affect which of these outcomes occurs, including the strength of the target's self-perceptions, the target's self-efficacy, and whether the perceiver

actually behaves in ways that help confirm their expectations (e.g., Eisenstadt \& Leippe, 1994).

Along these lines, the present research suggests that the ability of an individual to disconfirm another's beliefs of untrustworthiness may also depend on differences in the way people assess positive versus negative information about competence versus integrity. The 
findings support the notion that although people weigh positive information about others' competence more heavily than negative information about competence, they weigh negative information about others' integrity more heavily than positive information about integrity. Thus, this study offers clear implications for how interpersonal perceptions, specifically of untrustworthiness, may be disconfirmed.

\section{Implications for Impression Management Theory}

The current research can also inform impression management theory, specifically the portion of that literature focusing on defensive impression management tactics. Ashforth and Lee define these defensive behaviors as "reactive and protective actions intended to reduce a perceived threat" (1990: 622). These behaviors include apologies and denials (i.e., categorized as justifying and misrepresenting behaviors, respectively) as ways of avoiding blame (Ashforth \& Lee, 1990; Tedeschi \& Melburg, 1984).

The body of empirical research examining the effectiveness of defensive behaviors for managing impressions is small and offers mixed results. Stevens and Kristof (1995) measure defensive behaviors as well as other impression management tactics in their field study of employment interviews, but do not examine outcomes of the defensive tactics because they were so infrequent (i.e., only seven of twenty-four interviewees employed them). Wood and Mitchell (1981) found that nurse supervisors reported that they would be less likely to discipline a nurse when she apologized for a performance failure than if she did not apologize, but obtained mixed support for whether the apology decreased expectations of the nurse failing in the future. Moreover, Crant (1996) found that an apology was relatively less effective for maintaining positive impressions of a target than an excuse when responding to a failure. 
Yet our findings indicate that apology can be quite effective in responding to some threats, in this case a trust violation, given that apology was found to repair trust more successfully than denial after a competence-based violation. These results indicate that research on impression management could significantly benefit from considering the type of violation when exploring the effectiveness of these different tactics. Moreover, our findings suggest that defensive impression management tactics such as apology and denial can backfire if they are not aligned with actual guilt/innocence.

\section{Practical Implications}

This research also highlights two additional issues that deserve particular attention by managers who must sort through allegations and make attributions of trustworthiness. First, given strong support from both studies for the notion that trust is repaired more effectively when mistrusted parties apologize for violations concerning matters of competence and deny culpability for violations concerning matters of integrity, mistrusted parties may be tempted to apologize for competence-based violations even when they are innocent or to deny culpability for integrity-based violations even when they are guilty. And though the results from the second study may seem to mitigate these incentives by revealing that trust was generally lowered by discrepancies between the type of response and subsequent evidence concerning guilt/innocence, these penalties may be insufficient to outweigh the incentives for such lies to be used. When mistrusted parties were found to be guilty of an integrity-based violation, for example, there was virtually no detriment in the majority of the dependent measures (including perceived integrity) as a result of their having lied with a denial rather than having apologized from the beginning (see Table 6). This tendency to irrationally reward those who falsely deny integrity-based allegations, by penalizing them little more than those who admit their guilt, suggests that 
managers may need to create stronger incentives for honesty, either by placing more trust in those who have been honest or by placing less trust in those who have lied.

Moreover, given that the actual behavior discussed in these allegations was always the same (i.e., an improperly filed tax return), these studies suggest that violations of trust may often be ambiguous enough to be given different kinds of attributions. To the extent that this can occur, it seems likely that the success of trust repair efforts would largely depend on how the violations have been framed. Managers should, therefore, recognize that if a mistrusted party has responded to a violation with an apology or a denial, their decision of whether to attribute this incident to matters of competence or integrity is crucial because it will, in effect, determine whether they will trust that person in the future. Indeed, the implications of such attributions can be so dramatic that they can lead managers to exhibit greater trust in those who have confirmed guilt with an apology than in those who have claimed innocence.

\section{Limitations and Future Directions}

The phenomena that have been documented by this article represent important and fundamental aspects of interpersonal perception and relationship development. Thus, it is essential that managers develop a better understanding of how such influences occur. And though we believe the present studies offer some valuable insights into these issues, we also recognize that they should be further validated and extended in a variety of ways.

One limitation of the present studies is that they examined trust repair efforts in a laboratory rather than a field setting. As previously noted, we selected a laboratory-experimental method to heighten the internal validity of our analysis. Given the potential variety of trust violations and individuals' responses to those violations in the workplace, and the sense-making and social information processing that individuals experience in the aftermath of such violations, 
it would have been very difficult to develop a field test of our hypotheses that could have compared the effectiveness of different responses for different types of violations and provided a strong basis for examining causality, while also avoiding method bias and confounding effects. Our strategy, therefore, was to abstract some of the essential elements of such violations and responses so that we could study them in controlled settings (Locke, 1986). While this strategy should enhance external validity, additional research will be needed to assess the external validity of our findings more directly.

Future research is also needed to examine the applicability of the theory and findings to relationships of longer duration. Along these lines, one prior empirical study has indicated that although acknowledgements can be more effective than denials at re-establishing cooperation in social dilemmas after short interactions, denial can be more effective than acknowledgements after longer interactions (Bottom et al., 2002). Nevertheless, prior research offers no reason to expect that the observed interactions between the type of violation and type of response would fail to hold after a history of interaction is acquired. Thus, we expect that the practical implications of these findings will generalize to relationships of longer duration.

Third, it should be noted that although the types of responses under consideration were found to influence trust, neither of these responses appears to have repaired trust completely. Comparisons of means from Study 1 with those of the pilot study reveal that participants' assessments of the candidate's trustworthiness after an apology or denial had been offered were substantially higher than they had been immediately after a competence- or integrity-based allegation, but they were still generally lower than what they had been before such allegations were raised. Thus, to the extent that the means from the pilot study are representative of trust levels in the main studies immediately before and immediately after the allegation, it suggests 
that these responses represent only a partial solution for addressing trust violations, and that additional research is needed to determine how trust can be further repaired.

A fourth avenue for further study involves a comparison of apology and denial with other types of responses that might be used. The present studies, for example, have compared denial with an apology that involved an internal attribution (e.g., "It was entirely my fault"), but there are many occasions in which apologies involving external attributions (e.g., "I'm sorry I did it, but it happened because I was misinformed") or even no response can be used. Thus, it would be useful to compare the implications of denial, apology with an internal attribution, apology with an external attribution, and no response to provide a more comprehensive assessment of the responses we might use for trust repair. Moreover, it would be worthwhile to consider responses that are only available to organizations, such as the firing of employees and the addition of new rules, regulations, or oversight committees, to determine the conditions under which each of these responses would repair trust more effectively.

Finally, research might explore how the relative value of various trust repair efforts might differ across cultures. At present, this issue is largely a matter of speculation, given that it has yet to receive systematic attention. However, given the differences that have already been found in how work relationships differ across cultures, it is likely that there are also cultural differences in how individuals are able to repair trust. Cursory observations indicate that individuals in many Asian cultures are much less forgiving of violations such as bankruptcy and divorce than are individuals in the U.S., for example. However, there is a clear need for systematic work to help address this question. Indeed, given how little we truly know about the trust repair process, it is hoped that all of these questions receive significant attention in the future. 


\section{References}

Ashforth, B. E., \& Lee, R. T. (1990). Defensive behavior in organizations: A preliminary model. Human Relations, 43(7), 621-648.

Bagozzi, R. P., \& Phillips, L. W. (1982). Representing and testing organizational theories: A holistic construal. Administrative Science Quarterly, 27(3), 459-489.

Barber, B. (1983). The logic and limits of trust. New Brunswick, NJ: Rutgers University Press.

Baron, R. M., \& Kenny, D. A. (1986). The moderator-mediator variable distinction in social psychological research: Conceptual, strategic, and statistical considerations. Journal of Personality and Social Psychology, 51(6), 1173-1182.

Bell, B. E., \& Loftus, E. F. (1989). Trivial persuasion in the courtroom: The power of (a few) minor details. Journal of Personality and Social Psychology, 56(5), 669-679.

Bottom, W. P., Gibson, K., Daniels, S., \& Murnighan, J. K. (2002). When talk is not cheap: Substantive penance and expressions of intent in rebuilding cooperation. Organization Science, 13(5), 497-513.

Butler, J. K., Jr., \& Cantrell, R. S. (1984). A behavioral decision theory approach to modeling dyadic trust in superiors and subordinates. Psychological Reports, 55, 19-28.

Byrne, J. A. (2002). Restoring trust in corporate America: Business must lead the way to real reform. BusinessWeek, June 24, 30-35.

Cohen, J., \& Cohen, P. (1983). Applied regression / correlation analysis for the behavioral sciences. Hillsdale, NJ: Erlbaum.

Cook, J., \& Wall, T. (1980). New work attitude measures of trust, organizational commitment and personal need non-fulfillment. Journal of Occupational Psychology, 53, 39-52. 
Cook, T., \& Elmer, N. (1999). Bottom-up versus top-down evaluations of candidates' managerial potential: An experimental study. Journal of Occupational and Organizational Psychology, $72,423-439$.

Crant, J. M. (1996). Doing more harm than good: When is impression management likely to evoke a negative response? Journal of Applied Social Psychology, 26(16), 1454-1471.

Dirks, K. T., \& Ferrin, D. L. (2002). Trust in Leadership: Meta-analytic findings and implications for organizational research. Journal of Applied Psychology, 87(4), 611-628.

Dobbins, G., Lane, I., \& Steiner, D. (1988). A note on the role of laboratory methodologies in applied behavioural research: Don't throw out the baby with the bath water. Journal of Organizational Behavior, 9(3), 281-286.

Eisenstadt, D., \& Leippe, M. R. (1994). The self-comparison process and self-discrepant feedback: Consequences of learning you are what you thought you were not. Journal of Personality and Social Psychology, 67(4), 611-626.

Hendry, S. H., Peacock, D., \& Shaffer, D. R. (1989). On testifying on one's own behalf: Interactive effects of evidential strength and defendant's testimonial demeanor on mock jurors' decisions. Journal of Applied Psychology, 74(4), 539-545.

Jussim, L., Eccles, J., \& Madon, S. (1996). Social perception, social stereotypes, and teacher expectations: Accuracy and the quest for the powerful self-fulfilling prophecy. In M. P. Zanna (Ed.), Advances in experimental social psychology (Vol. 28, pp. 281-388). Orlando, FL: Academic.

Kee, H. W., \& Knox, R. E. (1970). Conceptual and methodological considerations in the study of trust and suspicion. Conflict Resolution, 14(3), 357-366. 
Kim, P. H., Diekmann, K. A., \& Tenbrunsel, A. E. (2003). Flattery may get you somewhere: The strategic implications of providing positive vs. negative feedback about ability vs. ethicality in negotiation. Organizational Behavior and Human Decision Processes, 90(2), 225-243.

Kramer, R. M. (1999). Trust and distrust in organizations: Emerging perspectives, enduring questions. Annual Review of Psychology, 50, 569-598.

Lewicki, R. J., \& Bunker, B. B. (1996). Developing and maintaining trust in work relationships. In R. M. Kramer \& T. R. Tyler (Eds.), Trust in organizations: Frontiers of theory and research (pp. 114-139). Thousand Oaks, CA: Sage.

Lewicki, R. J., \& Wiethoff, C. (2000). Trust, trust development, and trust repair. In M. Deutsch \& P. Coleman (Eds.), The handbook of conflict resolution: Theory and practice. San Francisco, CA: Jossey-Bass.

Madon, S., Jussim, L., \& Eccles, J. (1997). In search of the powerful self-fulfilling prophecy. Journal of Personality and Social Psychology, 72, 791-809.

Martijn, C., Spears, R., Van der Plight, J., \& Jakobs, E. (1992). Negativity and positivity effects in person perception and inference: ability versus morality. European Journal of Social Psychology, 22, 453-463.

Mayer, R. C., \& Davis, J. H. (1999). The effect of the performance appraisal system on trust for management: A field quasi-experiment. Journal of Applied Psychology, 84(1), 123-136.

Mayer, R. C., Davis, J. H., \& Schoorman, F. D. (1995). An integrative model of organizational trust. Academy of Management Review, 20(3), 709-734.

McKnight, D. H., Cummings, L. L., \& Chervany, N. L. (1998). Initial trust formation in new organizational relationships. Academy of Management Review, 23(3), 473-490. 
Meyerson, D., Weick, K. E., \& Kramer, R. M. (1996). Swift trust and temporary groups. In R. M. Kramer \& T. R. Tyler (Eds.), Trust in organizations: Frontiers of theory and research (pp. 166-195). Thousand Oaks, CA: Sage.

Ohbuchi, K., Kameda, M., \& Agarie, N. (1989). Apology as aggression control: Its role in mediating appraisal of and response to harm. Journal of Personality and Social Psychology, $56(2), 219-227$.

Pancer, S., Brown, S., \& Barr, C. (1999). Forming impressions of political leaders: A crossnational comparison. Political Psychology, 20, 345-368.

Penrod, S., \& Cutler, B. (1995). Witness confidence and witness accuracy: Assessing their forensic relation. Psychology, Public Policy, and Law, 1(4), 817-845.

Reeder, G. D., \& Brewer, M. B. (1979). A schematic model of dispositional attribution in interpersonal perception. Psychological Review, 86(1), 61-79.

Reeder, G. D., \& Coovert, M. (1986). Revising an impression of morality. Social Cognition, 4, 1-17.

Riordan, C. A., Marlin, N. A., \& Kellogg, R. T. (1983). The effectiveness of accounts following transgression. Social Psychology Quarterly, 46, 213-219.

Robinson, S. L., \& Rousseau, D. M. (1994). Violating the psychological contract: Not the exception but the norm. Journal of Organizational Behavior, 15, 245-259.

Ross, D. F., Ceci, S. J., Dunning, D., \& Toglia, M. P. (1994). Unconscious transference and mistaken identity: When a witness misidentifies a familiar but innocent person. Journal of Applied Psychology, 79(6), 918-930.

Rousseau, D. M., Sitkin, S. B., Burt, R. S., \& Camerer, C. (1998). Not so different after all: A cross-discipline view of trust. Academy of Management Review, 23, 393-404. 
Schindler, P. L., \& Thomas, C. C. (1993). The structure of interpersonal trust in the workplace. Psychological Reports, 73, 563-573.

Schlenker, B. R. (1980). Impression management: The self-concept, social identity, and interpersonal relations. Monterey, CA: Brooks/Cole.

Schwartz, G., Kane, T., Joseph, J., \& Tedeschi, J. T. (1978). The effects of remorse on the reactions of a harm-doer. British Journal of Social Psychology, 17, 293-297.

Sigal, J., Hsu, L., Foodim, S., \& Betman, J. (1988). Factors affecting perceptions of political candidates accused of sexual and financial misconduct. Political Psychology, 9(2), 273-280.

Slovic, P. (1993). Perceived risk, trust, and democracy. Risk Analysis, 13, 675-682.

Snyder, M., \& Stukas, A. A., Jr. (1999). Interpersonal processes: The interplay of cognitive, motivational, and behavioral activities in social interaction. Annual Review of Psychology, $50,273-303$

Stevens, C. K., \& Kristof, A. L. (1995). Making the right impression: A field study of applicant impression management during job interviews. Journal of Applied Psychology, 80(5), 587606.

Tedeschi, J. T., \& Melburg, V. (1984). Impression management and influence in the organization. Research in the Sociology of Organizations, 3, 31-58.

Tyler, T. R., \& Kramer, R. M. (1996). Wither trust? In R. M. Kramer \& T. R. Tyler (Eds.), Trust in organizations: Frontiers of theory and research (pp. 1-15). Thousand Oaks, CA: Sage.

Wood, R. E., \& Mitchell, T. R. (1981). Manager behavior in a social context: The impact of impression management on attributions and disciplinary actions. Organizational Behavior and Human Decision Processes, 28, 356-378. 